\title{
Conditions of the male breast: Gynaecomastia and male breast cancer (Review)
}

\author{
LAILA ALALI ${ }^{1}$, HELEN HONARPISHEH $^{2}$, ABEER SHAABAN $^{3}$ and VALERIE SPEIRS ${ }^{1,2}$ \\ ${ }^{1}$ Leeds Medical School, ${ }^{2}$ Leeds Institute of Molecular Medicine, University of Leeds, Leeds LS2 9JT; \\ ${ }^{3}$ St James's Institute of Oncology, St James's University Hospital, Leeds LS9 7TF, UK
}

Received March 27, 2009; Accepted July 6, 2009

DOI: 10.3892/mmr_00000213

\begin{abstract}
Breast disease most commonly affects females; however, a small percentage of men are also affected. Understandably given its low incidence, awareness of male breast disease is low, particularly among the general population. We searched the Medline database from 1950 onwards using the search terms male, breast, neoplasms and gynaecomastia, and reviewed the conditions associated with male breast disease, examining some of the risk factors and discussing how these conditions are diagnosed and treated, and finally putting forward some suggestions for their future management.
\end{abstract}

\section{Contents}

1. Introduction

2. Diagnosis and pathology

3. Risk factors

4. Treatment

5. Conclusions

\section{Introduction}

Breast disease most commonly affects females; however, a small percentage of men are also affected. Awareness of male breast disease, particularly among the general public, is low. Men do, however, possess a small amount of breast tissue, which makes them susceptible to breast disease, in particular male breast cancer (MBC) and the benign condition gynaecomastia $(1,2)$. This review highlights some of the risk factors associated with the two conditions, and describes their diagnosis and treatment.

Correspondence to: Dr Valerie Speirs, Leeds Institute of Molecular Medicine, Wellcome Trust Brenner Building, St James's University Hospital, Leeds LS9 7TF, UK

E-mail: v.speirs@leeds.ac.uk

Key words: male breast cancer, gynaecomastia, males

\section{Diagnosis and pathology}

Male breast cancer. Breast cancer in men may be uncommon, but it does occur (3). Male breast cancer (MBC) is responsible for less than $1 \%$ of all breast cancers, though there is some variation in the literature as to the exact figure (3-5). This is in contrast to female breast cancer (FBC), which is the most common female cancer worldwide. According to figures from Cancer Research UK, approximately 300 men are diagnosed with MBC in the UK per year (6). This small number of cases has has made it impossible to set up randomised prospective international trials to determine the most effective way of managing $\mathrm{MBC}$, and it is currently approached in the same way as $\mathrm{FBC}(7,8)$.

The incidence of $\mathrm{MBC}$ is rising, as reported in an agecorrected study conducted in the US, where increases of up to 26\% were been noted between 1973 and 1998 (5). Unpublished data obtained from UK Cancer Registries suggest that the incidence in the UK is also increasing; this is reflected in figures obtained from Cancer Research UK (Fig. 1). There is, moreover, little evidence to suggest a positive change in the male mortality rate, while in females the mortality rate is decreasing. This may be due to the lack of a thorough understanding of MBC (9).

In the majority (75\%) of cases, MBC patients present to their GP with a painless lump in the subareolar region of the breast, eccentric to the nipple $(3,4,7,8)$. In some instances, patients may present with other symptoms, such as pain and nipple involvement. Pain is uncommon, occurring in only $5 \%$ of cases $(1,4)$. Changes in the nipple can include nipple retraction, nipple discharge, and even ulceration (4). Although rare and occurring in only $1 \%$ of MBC cases, it is crucial to consider Paget's disease when relying on clinical features for diagnosis. Paget's disease is a type of breast cancer which originates in the ducts of the breast but spreads to the nipple, causing changes to the nipple skin. Its presentation is often similar to that of other skin conditions, such as eczema; reddening of the skin and itchiness is often observed, and bleeding and crusting is common $(1,4)$.

The most frequently occurring type of MBC in terms of histology is invasive ductal carcinoma of no special type, which accounts for $90 \%$ of MBCs $(4,10)$. Papillary carcinoma is the second most common type, with a 2-fold increased incidence in males compared to females (11). Most histopathological 


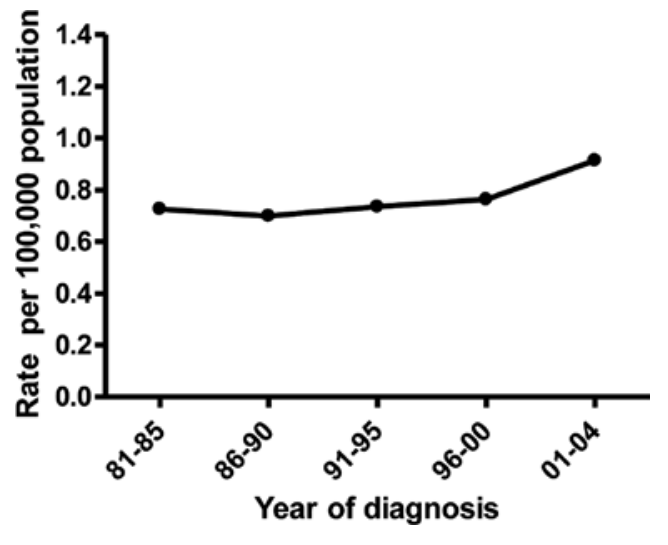

Figure 1. Age-standardised breast cancer incidence rates for the UK showing a gradual rise in incidence over the last ten years.

subtypes of breast cancer observed in females have also been reported in males; however, most men do not have well-developed lobules, making lobular carcinoma exceedingly rare $(3,4,10)$. Ductal carcinoma in situ, often of a low grade, has been reported in $5-15 \%$ of cases (12). Hormone receptor expression is extremely common in $\mathrm{MBC}$, with figures of up to $90 \%$ reported, compared to only $60-70 \%$ in $\operatorname{FBC}(3,13)$. Previous studies report that the rate of HER2 in MBC is similar to that found in FBC $(14,15)$. However, due to the improved standardisation of HER2 testing, recent data indicate that HER2 amplification is infrequent in male breast tumours, accounting for only $5 \%$ of cases $(16,17)$.

Gynaecomastia. Gynaecomastia is a condition involving benign proliferation of the glandular tissue in the male breast, resulting in non-cancerous breast enlargement $(2,18)$. It is often associated with life stages characterised by significant hormonal imbalances, e.g., the neonatal period, puberty and old age (18). Neonates are at risk of gynaecomastia since they are exposed to high levels of estrogen from the mother's placenta. This type of gynaecomastia is known as transient, and is estimated to be present in 60-90\% of neonates (18-20). Pubertal gynaecomastia affects $48-64 \%$ of boys. The cause is not fully understood, but is presumed to be due to an imbalance in estrogen and androgen. Gynaecomastia in late life is typically observed in men over 50 years of age. Traces of gynaecomastia reported in as many as $55 \%$ of autopsies suggest that it often goes undiagnosed (18-20).

The above-mentioned types of gynaecomastia associated with hormone imbalances are examples of true gynaecomastia. Another class of gynaecomastia is pseudo-gynaecomastia. Physical examination is required to differentiate between the two types (21). Pseudo-gynaecomastia is a condition where the male breast is enlarged due to the deposition of adipose tissue, and is often associated with obesity $(2,21)$. In contrast, true gynaecomastia is an increase in the hyperplasia of the breast tissue. It often presents as a firm rubbery mass of tissue in the subareolar area. Although the mass is firm to the touch, it is usually not hard, and the lesion is commonly bilateral and symmetrical. However, in certain cases it can be unilateral and asymmetrical. As a similar presentation is commonly observed in $\mathrm{MBC}$, in such cases further testing is required to rule out cancer $(2,8,18,20)$. Gynaecomastia is more common than breast cancer in the male population, with an estimated $40-65 \%$ of healthy males affected by the disease $(18,20)$. Variations in numbers may be due to the interchangeable use of clinical and histological definitions, and due to controversy over what actually qualifies as clinical gynaecomastia. For example, Cakan and Kamat defined gynaecomastia as breast glandular tissue enlarged by $\geq 0.5 \mathrm{~cm}$ in diameter (19), while Daniels and Layer required patients to have breast tissue enlarged by $\geq 2 \mathrm{~cm}$ in diameter for a diagnosis of gynaecomastia to be made (22).

\section{Risk factors}

Male breast cancer. The rarity of MBC makes it difficult to determine the true causes of the disease; few studies have had a sufficiently large sample size to ensure significant findings (9). Fortunately, researchers can use information gathered from studies on FBC to design their studies and to determine whether the results are the same for MBC. There are many factors potentially linked to MBC (Table I), but these relationships need further investigation for significance to be determined.

A positive family history of breast cancer is found in approximately $20 \%$ of MBC patients, and increases the risk by as much as 3 -fold $(9,10,23)$. There are certain genetic mutations that show a clear association with $\mathrm{MBC}$, and others that are in the early stages of investigation. Breast cancer in men is common in families that carry the BRCA2 mutation. Most inherited MBCs are thought to be associated with a mutation in the $B R C A 2$ gene, which is reported to increase the risk of $\mathrm{MBC}$ by 80 - to 100 -fold compared with the general male population (24). This gene is located on chromosome 13q12-13 and is thought to be involved in DNA repair, as it is responsible for the regulation of the activity of the DNA repair gene RAD51 $(9,10,23,25)$. Despite this strong link, the percentage of individuals with a BRCA2 mutation varies significantly among different populations. A study on Icelandic men found the $B R C A 2$ mutation in $40 \%$ of male cancer patients, whereas a study in California discovered the mutation in only $4 \%$ of patients. These figures could be influenced by small sample size, or could be indicative of genetic differences in individuals of different ethnic backgrounds $(9,10,23)$.

Cowden syndrome is an autosomal dominant condition caused by a germline mutation in the PTEN gene that makes individuals susceptible to benign or malignant neoplasms. As PTEN is a tumour suppressor gene, any mutations of this gene prevent the suppression of tumours growing in the breast. It has been suggested that PTEN only plays a role in cancer in individuals affected by Cowden syndrome $(2,23,25)$.

CHEK2 is another gene that is potentially associated with MBC. It is a cell-cycle checkpoint kinase and, like BRCA2, has a role in DNA repair. It has been proposed that CHEK2*1100delC, a variant identified by a CHEK2 Breast Cancer Consortium study, is responsible for up to $9 \%$ of MBCs and increases the risk of MBC by approximately 10 -fold. However, other related studies that looked for the mutation globally in MBC have argued against this finding $(5,9,23)$.

A study of germline mutations in the androgen receptor $(A R)$ gene demonstrated a possible associated predisposition to MBC (26). Again, this finding is controversial; other studies claim that there is no significant evidence to support 
Table I. Risk factors associated with male breast cancer (MBC).

\begin{tabular}{ll}
\hline Risk factor & \multicolumn{1}{c}{ Explanation } \\
\hline Age & Risk of MBC increases with age (5). \\
Ethnicity & Incidence of MBC seems to be higher in Ashkenazi Jews $(1,4)$. \\
Genetics & Family history and $B R C A 2$ genetic mutations increase risk of MBC (23). \\
Childlessness & Having no children seems to increase the risk by 5-fold in comparison to men who \\
have children, possibly related to infertility (hormonal) (8). & Some occupational hazards increase the risk of MBC (8). \\
Environmental exposure & Increased estrogen levels are related to MBC (23). \\
\hline Hormonal factors &
\end{tabular}

Table II. Summary of the main causes of gynaecomastia.

\begin{tabular}{|c|c|}
\hline Cause & Explanation \\
\hline Puberty & Transient hormone changes (56). \\
\hline Hormonal imbalances & $\begin{array}{l}\text { Hormone-based therapies, e.g. for the treatment of prostate cancer, have been } \\
\text { associated withgynaecomastia (33). }\end{array}$ \\
\hline Drugs (prescription and those of abuse) & No clear explanation in the absence of randomised trials $(8,19,20,33)$. \\
\hline Hepatic cirrhosis & Alcoholic cirrhosis (57). \\
\hline Hypogonadism & Often secondary to Klinefelter's syndrome (58). \\
\hline Testicular tumours & Tumours can elevate levels of estrogen and repress testosterone $(59,60)$. \\
\hline Hyperthyroidism & $\begin{array}{l}\text { Estrogenic effects of active metabolites of dehydroepiandrosterone and its } \\
\text { sulphate (61). }\end{array}$ \\
\hline Chromosomal abnormalities & Klinefelter's syndrome is commonly associated with gynaecomastia (20). \\
\hline
\end{tabular}

This is a non-exhaustive list, and many of the conditions are inter-related

this link $(9,23,27)$. Instead, it has been suggested that the $A R$ gene contributes to $\mathrm{MBC}$ by affecting the ratio of estrogen and androgen $(4,9,23)$.

CYP17 codes for cytochrome $\mathrm{P} 450 \mathrm{c} 17 \alpha$, which is involved in estrogen and androgen biosynthesis. A polymorphism in this gene leads to an increase in steroid hormone production. As a result, it is believed to be a key gene in MBC. Further studies are needed using larger sample sizes to substantiate this association $(4,9,23)$.

Evidence suggests that some occupational hazards increase the risk of employees developing breast cancer. Electromagnetic fields (EMFs) may affect workers by reducing the amount of melatonin produced by the pineal gland. Studies have found that melatonin may prevent the growth of breast cancer cells, and that reduced levels affect breast tumour development $(23,28)$. Although these studies have shown an associated increase in risk, it is difficult to compare and relate the results, as measurements of the amount of exposure to EMFs were not noted (23). Additional occupational environmental factors linked to the increased risk of breast cancer have been proposed, but the exact mechanisms behind these links are unclear. These include high temperatures and environments characteristic of soap and perfume manufacturing $(4,28)$.

Hormonal factors are arguably the main risk factor for MBC. Conditions such as liver cirrhosis and obesity can affect estrogen levels, and have therefore been considered as additional risk factors for MBC. Liver cirrhosis can result in the elevation of estrogen and the reduction of testosterone levels, which may predispose individuals to MBC. Studies by Sorensen et al showed a 4-fold increase in the risk of MBC in individuals with cirrhosis (29), although other researchers have suggested this increase is insignificant (30). However, this finding appears to be supported by a Swedish study, which found a difference in the incidence of MBC in alcoholics (31).

Obesity doubles the risk of $\mathrm{MBC}$, as the condition results in increased estrogen production. There seems to be positive correlation between circulating estrogen and body weight $(4,23)$. The increasing incidence of obesity is now a major problem in Western society, and the Department of Health in the UK estimates that by $201033 \%$ of men will be obese (32), with a possible concomitant rise in $\mathrm{MBC}(4,23)$. 
Gynaecomastia. Gynaecomastia develops when there is an imbalance in estrogen and androgen levels; breast tissue growth is stimulated by estrogen, whereas androgens exert an inhibitory effect. There are a number of factors that can increase the risk of imbalance between these two hormones (20).

The main causes of gynaecomastia are presented in Table II. One of the most important factors associated with the condition is Kleinfelter's syndrome. Gynaecomastia is reported in approximately $80 \%$ of cases of Kleinfelter's syndrome (20). Some studies propose that the extra $\mathrm{X}$ chromosome in the $\mathrm{XXY}$ genotype is responsible for the increase in the risk of gynaecomastia and MBC (20). Various studies have found no significant evidence linking gynaecomastia and MBC $(4,23)$. However, it is evident that Kleinfelter's syndrome does link the two conditions, as it is considered to cause both, and there is published data to suggest that individuals with Kleinfelter's have a 20- to 50-fold increased risk of $\operatorname{MBC}(4,20,21)$.

A number of drugs have been associated with the development of gynaecomastia, but the associated mechanisms are not fully understood. These drugs include illegal narcotics such as marijuana, heroin and amphetamines, but also many prescription drugs, such as peptic ulcer, cardiovascular and psychoactive drugs, and even antibiotics $(8,19,20,33)$. More recently, it has been reported that HIV-positive patients tend to develop gynaecomastia as a result of HAART, an anti-HIV drug (34). These findings must be considered by health professionals when prescribing drugs to male patients for various medical conditions.

Familial gynaecomastia, a rarity with only a handful of cases reported worldwide (35-37), has been associated with functional abnormalities of the cytochrome p450 gene (CYP19). This gene encodes aromatase, one the key enzymes involved in estrogen biosynthesis.

\section{Treatment}

\section{Male breast cancer}

Treatment of localised disease. Treatment of MBC is usually very similar to that of FBC. Cancer in the early stages is usually treated with modified radical mastectomy and axillary node clearance. Recently, sentinel lymph node biopsy has been shown to be accurate and feasible in the treatment of clinically node-negative MBC (38). Several studies have also suggested that follow-up radiotherapy may be beneficial to men. A number of studies support this mode of treatment for preventing recurrence, but agree that it has no overall affect on survival $(8,10)$.

Adjuvant hormonal therapy is an important factor in the treatment of MBC, since $90 \%$ of cases are hormone-receptor positive $(4,5)$. Tamoxifen is the gold standard for early and advanced FBC $(4,7,9)$, but its efficacy may be underestimated as most studies have been carried out for a maximum of 2 years, while in females tamoxifen has an optimum affect after 5 years of therapy (4). Tamoxifen is the first-line hormonal therapy for the treatment of hormone-positive primary male breast carcinoma. To date, there have been no randomised controlled trials investigating the $\mathrm{MBC}$ response rate to tamoxifen and any associated side effects. Previous reports suggest that tamoxifen treatment is safe and well tolerated by males. The agonistic effect of tamoxifen on the endometrium is non-existent in men, and hot flushes, a common side effect in females, are less severe in male patients $(5,39)$. However, its success does not mean that it is suitable in all cases, as tamoxifen leads to side effects in $62.5 \%$ of users (41). These side effects can range from mood changes and depression to more physical changes such as weight gain, hair loss and even impotence $(4,8)$. A telephone survey showed that sexual dysfunction was the main cause of tamoxifen discontinuation in men (40). Newer aromatase inhibitors, which are proving superior to tamoxifen in a postmenopausal $\mathrm{ER} \alpha^{+}$setting in FBC (42-44), have yet to be fully investigated in MBC. However, there are encouraging early reports documenting the successful use of letrozole in the clinical setting in male subjects $(45,46)$. These agents provide an additional treatment strategy for MBC. With respect to adjuvant chemotherapy, benefits have been reported in some MBC patients, but relatively few studies have been conducted to confirm these findings. Therefore, the risks need to be thoroughly assessed on a patient-specific basis $(1,9)$.

Treatment of advanced disease. For decades, hormone treatment has been the main line therapy for advanced breast cancer in men. Ablative therapy (orchidectomy) and more recently hormone treatment have been applied with success in metastatic MBC; the latter is psychologically more acceptable to men, and is associated with lower morbidity $(47,48)$. Tamoxifen remains the first-line treatment, but anastrazole and letrazole have produced some objective responses and are more likely to be widely used $(45,49)$. Systemic chemotherapy is another option in the metastatic setting, but is usually a second- or third-line therapy since most tumours receive hormonal treatment. Chemotherapy is used in particular in patients with hormone-negative tumours. Response rates vary from $13 \%$ for single-agent fluouracil administration to as high as $67 \%$ for FAC combination therapy (48). No information exists regarding the use of trastuzumab in the adjuvant setting for advanced MBC, but in view of the remarkable benefits it has had in FBC the drug should also be used for the treatment of HER2-positive male breast tumours (4). As in FBC patients, sequential hormone and chemotherapy treatment is preferred to concurrent administration (4).

\section{Gynaecomastia}

Treatment. The treatment of gynaecomastia depends on the cause. When it results from a primary condition, it needs to be addressed and treated. In about $25 \%$ of cases, there is no underlying cause, so treatment is necessary only in the event of patient distress such as embarrassment or pain $(19,20)$. Two selective estrogen receptor modulators (SERMS) have been evaluated for the treatment of gynaecomastia. Of these, tamoxifen has shown high efficacy, leading to the complete regression of gynaecomastia in approximately $70 \%$ of cases $(20,21)$. Raloxifene was effective in reducing the size of pubertal gynaecomastia; however, this finding was demonstrated in an uncontrolled study involving 10 cases (50). A randomised, double blind, placebo-controlled trial found the effects of the aromatase inhibitor anastrozole ineffective in reducing pubertal gynaecomastia (51). Despite encouraging results with SERMS, surgery is still the preferred mode of treatment for gynaecomastia. Recently, less invasive surgical techniques have been introduced, including mammotome 
excision of gynaecomastia under ultrasound guidance (52). However, surgical intervention is not recommended for pubertal gynaecomastia until puberty is complete, as hormonal imbalances can cause recurrence, and as $80 \%$ of cases spontaneously resolve within 2 years $(18,19)$.

\section{Conclusions}

Gynaecomastia is a relatively common benign enlargement of the male breast. The relationship between gynaecomastia and $\mathrm{MBC}$ has been investigated, but to date there is no convincing evidence that gynaecomastia is associated with a higher risk of $\mathrm{MBC}$ development. The incidence of $\mathrm{MBC}$ is increasing, and further research is required to fully understand its cause and subsequent treatment. Considering that the incidence of obesity is also increasing significantly and doubles the risk of $\mathrm{MBC}$, research on obesity and obesity prevention programmes may be interlinked with $\operatorname{MBC}(23,32)$. MBC also has a strong genetic link, in particular with $B R C A 2$. Other as yet unidentified genes may also be linked to MBC. These may include FGFR2, TNRC9, MAP3K1 and LSP1, which were identified by SNP analysis as susceptibility genes in FBC (53). Large multicentre collaborative studies are required to extrapolate these findings to $\mathrm{MBC}$ and to confirm any significant relationships.

It is crucial to foster an awareness of MBC, not only to enable early diagnosis, but also to avoid the stigmatisation and to reduce the psychological burden experienced by many MBC patients $(1,54,55)$.

\section{Acknowledgements}

We thank the following organisations for providing statistics: Northern and Yorkshire Cancer Registration and Information Service, Scottish Cancer Registry, North West Cancer Intelligence Service, Oxford Cancer Intelligence Unit, Eastern Cancer Registration and Information Centre, Trent Cancer Registry, Thames Cancer Registry, Welsh Cancer Intelligence and Surveillance Unit, and West Midlands Cancer Intelligence Unit. Data from the South and West Cancer Intelligence Service and the Northern Ireland Cancer Registry were obtained online (http://www.swpho.nhs.uk/ and http://www.qub.ac.uk/ research-centres/nicr/, respectively). Our male breast cancer programme is supported by the Breast Cancer Campaign.

\section{References}

1. Peate I: Caring for men with breast cancer: causes, symptoms and treatment. Br J Nurs 10: 975-981, 2001.

2. Kopans DB: The Male Breast in Breast Imaging. 3rd edition, Lippincott Williams \& Wilkins, Baltimore, pp671-690, 2006.

3. Wertkin MG: Diagnosis and management of male breast cancer in the community hospital setting (letter to editor). Breast J 12 : 188-189, 2006.

4. Fentiman IS, Fourquet A and Hortobagyi GN: Male breast cancer. Lancet 367: 595-604, 2006.

5. Giordano SH, Cohen DS, Buzdar AU, Perkins $G$ and Hortobagyi GN: Breast carcinoma in men: a population-based study. Cancer 103: 432-433, 2005.

6. Williams BG, Iredale R, Brian K, France E, Barrett-Lee P and Gray J: Experience of men with breast cancer: an explanatory focus group study. Br J Cancer 89: 1834-1836, 2003.

7. Rossmann ED, Liljegran A and Bergh J: Male breast cancer how to treat? Breast Cancer Online 10: e15, 2007.
8. Meguerditchian A, Falardeau M and Martin G: Male breast carcinoma. Can J Surg 45: 296-302, 2002.

9. Nahleh Z and Girnius S: Male breast cancer: a gender issue. Nat Clin Pract Oncol 3: 428-437, 2006.

10. Giordano SH, Buzdar AU and Hortobaghi GN: Breast cancer in men. Ann Intern Med 137: 678-687, 2002.

11. Burga AM, Fadare O, Lininger RA and Tavassoli FA: Invasive carcinomas of the male breast: a morphologic study of the distribution of histologic subtypes and metastatic patterns in 778 cases. Virchows Arch 449: 507-512, 2006.

12. Pappo I, Wasserman I and Halevy A: Ductal carcinoma in situ of the breast in men: a review. Clin Breast Cancer 6: 310-314, 2005.

13. Girodana SH: A review of the diagnosis and management of male breast cancer. Oncologist 10: 471-479, 2005.

14. Leach IH, Ellis IO and Elston CW: c-erb-B-2 expression in male breast carcinoma. J Clin Pathol 45: 942, 1992.

15. Blin N, Kardas I, Welter C, et al: Expression of the c-erbB2 proto-oncogene in male breast carcinoma: lack of prognostic significance. Oncology 50: 408-411, 1993.

16. Bloom KJ, Govil H, Gattuso P, Reddy V and Francescatti D: Status of HER-2 in male and female breast carcinoma. Am J Surg 182: 389-392, 2001.

17. Muir D, Kanthan R and Kanthan SC: Male versus female breast cancers. A population-based comparative immunohistochemical analysis. Arch Pathol Lab Med 127: 36-41, 2003.

18. Dixon JM and Sainsbury JRC: Handbook of Diseases of the Breast. 2nd edition, Churchill and Livingstone, Edinburgh, pp54-56, 1998.

19. Cakan N and Kamat D: Gynecomastia: evaluation and treatment recommendations for primary care providers. Clin Pediat 46: 487-490, 2007.

20. Bembo SA and Carlson HE: Gynaecomastia: its features, and when and how to treat. Cleve Clin J Med 71: 511-517, 2004.

21. Glen D and Braunstein MD: Gynecomastia. N Engl J Med 357: 1229-1237, 2007.

22. Daniels IR and Layer GT: How should gynaecomastia be managed? ANZ J Surg 73: 213-216, 2003.

23. Weiss JR, Moysich KB and Swede H: Epidemiology of male breast cancer. Cancer Epidemiol Biomarkers Prev 14: 20-26, 2005.

24. Syrjakoski K, Jantti J, Kallioniemi A and Karhu R: Mutations in the BRCA2 interacting DSS1 are not a risk factor for male breast cancer. Int J Cancer 120: 444-446, 2006.

25. Martin A and Weber BL: Genetic and hormonal risk factors in breast cancer. J Natl Cancer Inst 92: 1126-1135, 2000.

26. Wooster R, Mangion J, Eeles R, et al: A germline mutation in the androgen receptor gene in 2 brothers with breast cancer and Reifenstein syndrome. Nat Genet 2: 132-134, 1992.

27. Syrjakoski K, Hyytinen ER, Kuukasjarvi T, et al: Androgen receptor gene alterations in Finnish male breast cancer. Breast Cancer Res Treat 77: 167-170, 2003.

28. Tynes T: Electromagnetic fields and male breast cancer. Biomed Pharmacother 47: 425-427, 1993.

29. Sorensen HT, Friis S, Olsen JH, et al: Risk of breast cancer in men with liver cirrhosis. Am J Gastroenterol 93: 231-233, 1998.

30. Lenfant-Pejovic $\mathrm{MH}$, Mlika-Cabanne $\mathrm{N}$, Bouchardy $\mathrm{C}$ and Auquier A: Risk factors for male breast cancer: a Franco-Swiss case-control study. Int J Cancer 45: 661-665, 1990.

31. Weiderpass E, Ye W, Adami HO, Vainio H, Trichopoulos D and Nyren O: Breast cancer risk in male alcoholics in Sweden. Cancer Causes Control 12: 661-664, 2001.

32. DepartmentofHealth:PublicHealth.Healthimprovement.Obesity. http://www.dh.gov.uk/en/Publichealth/Healthimprovement/ Obesity/index.htm.

33. Wise GJ, Roorda AK and Kalter R: Male breast disease. J Am Coll Surg 200: 255-269, 2005.

34. Gewurz BE, Dezube BJ and Pantanowitz L: HIV and the breast. AIDS Reader 15: 392-396, 2005.

35. Binder G, Iliev DI, Dufke A, et al: Dominant transmission of prepubertal gynecomastia due to serum estrone excess: hormonal, biochemical, and genetic analysis in a large kindred. J Clin Endocrinol Metab 90: 484-492, 2005.

36. Stratakis CA, Vottero A, Brodie A, et al: The aromatase excess syndrome is associated with feminization of both sexes and autosomal dominant transmission of aberrant p450 aromatase gene transcription. J Clin Endocrinol Metab 83: 1348-1357, 1998.

37. Berkovitz GD, Guerami A, Brown TR, MacDonald PC and Migeon CJ: Familial gynecomastia with increased extraglandular aromatization of plasma carbon 19-steroids. J Clin Invest 75: 1763-1769, 1985. 
38. Boughey JC, Bedrosian I, Meric-Bernstam F, et al: Comparative analysis of sentinel lymph node operation in male and female breast cancer patients. J Am Coll Surg 203: 475-480, 2006.

39. Patterson JS, Battersby LA and Bach BK: Use of tamoxifen in advanced male breast cancer. Cancer Treat Rep 64: 801-804, 1980.

40. Anelli TF, Anelli A, Tran KN, Lebwohl DE and Borgen PI: Tamoxifen administration is associated with a high rate of treatment-limiting symptoms in male breast cancer patients. Cancer 74: 74-77, 1994.

41. Donegan WL and Redlich PN: Breast cancer in men. Surg Clin North Am 76: 343-363, 1996.

42. Baum M, Budzar AU, Cuzick J, et al; ATAC Trialists' Group: Anastrozole alone or in combination with tamoxifen versus tamoxifen alone for adjuvant treatment of postmenopausal women with early breast cancer: first results of the ATAC randomised trial. Lancet 359: 2131-2139, 2002.

43. Coombes RC, Hall E, Gibson LJ, et al: Intergroup Exemestane Study. A randomized trial of exemestane after two to three years of tamoxifen therapy in postmenopausal women with primary breast cancer. N Engl J Med 350: 1081-1092, 2004.

44. Goss PE, Ingle JN, Martino S, et al: A randomized trial of letrozole in postmenopausal women after five years of tamoxifen therapy for early-stage breast cancer. N Engl J Med 349: 1793-1802, 2003.

45. Zabolotny BP, Zalai CV and Meterissian SH: Successful use of letrozole in male breast cancer: a case report and review of hormonal therapy for male breast cancer. J Surg Oncol 90: 26-30, 2005.

46. Arriola E, Hui E, Dowsett M and Smith IE: Aromatase inhibitors and male breast cancer. Clin Transl Oncol 9: 192-194, 2007.

47. Meyskens FL Jr, Tormey DC and Neifeld JP: Male breast cancer: a review. Cancer Treat Rev 3: 83-93, 1976.

48. Jaiyesimi IA, Buzdar AU, Sahin AA and Ross MA: Carcinoma of the male breast. Ann Int Med 117: 771-777, 1992.

49. Giordano SH, Valero V, Buzdar AU and Hortobagyi GN: Efficacy of anastrozole in male breast cancer. Am J Clin Oncol 25: 235-237, 2002.
50. Lawrence SE, Faught KA, Vethamuthu J and Lawson ML: Beneficial effects of raloxifene and tamoxifen in the treatment of pubertal gynecomastia. J Pediatr 145: 71-76, 2004.

51. Plourde PV, Reiter EO, Jou HC, et al: Safety and efficacy of anastrozole for the treatment of pubertal gynecomastia: a randomized, double-blind, placebo-controlled trial. J Clin Endocrinol Metab 89: 4428-4433, 2004.

52. Iwuagwu OC, Calvey TA, Ilsley D and Drew PJ: Ultrasound guided minimally invasive breast surgery (UMIBS): a superior technique for gynecomastia. Ann Plast Surg 52: 131-133, 2004.

53. Easton DF, Pooley KA, Dunning AM, et al: Genome-wide association study identifies novel breast cancer susceptibility loci. Nature 447: 1087-1093, 2007.

54. Iredale R, Brian K, Williams B, France E and Gray J: The experiences of men with breast cancer in the United Kingdom. Eur J Cancer 42: 334-341, 2006.

55. Brain K, Williams B, Iredale R, France E and Gray J: Psychological distress in men with breast cancer. J Clin Oncol 24: 95-101, 2006.

56. Lazala C and Saenger P: Pubertal gynecomastia. J Pediatr Endocrinol Metab 15: 553-560, 2002.

57. Cavanaugh J, Niewoehner CB and Nuttall FQ: Gynecomastia and cirrhosis of the liver. Arch Intern Med 150: 563-565, 1990.

58. Pawlowski E and Nield LS: Gynecomastia and hypogonadism. Clin Pediatr 47: 313-315, 2008.

59. Venara M, Rey R, Bergadá I, Mendilaharzu H, Campo S and Chemes H: Sertoli cell proliferations of the infantile testis: an intratubular form of Sertoli cell tumor? Am J Surg Pathol 25: 1237-1244, 2001.

60. Zarrilli S, Lombardi G, Paesano L, et al: Hormonal and seminal evaluation of Leydig cell tumour patients before and after orchiectomy. Andrologica 32: 147-154, 2000.

61. Tagawa N, Takano T, Fukata S, et al: Serum concentration of androstenediol and androstenediol sulfate in patients with hyperthyroidism and hypothyroidism. Endocr J 48: 345-354, 2001. 